\title{
Fertility preservation in endometrial cancer patients: options, challenges and perspectives
}

\author{
Milan Terzic ${ }^{1,2,3 a}$ (D), Melanie Norton ${ }^{4}$, Sanja Terzic ${ }^{2}$, Gauri Bapayeva ${ }^{1}$ and Gulzhanat Aimagambetova ${ }^{5 b}$ (iD) \\ ${ }^{1}$ Clinical Academic Department of Women's Health, National Research Center for Mother and Child Health, University Medical Center, Astana, Kazakhstan \\ ${ }^{2}$ Department of Medicine, Nazarbayev University, School of Medicine, Astana, Kazakhstan \\ ${ }^{3}$ Department of Obstetrics, Gynecology and Reproductive Sciences, University of Pittsburgh, School of Medicine, Pittsburgh, Pennsylvania, USA \\ ${ }^{4}$ Whittington Hospital, Department of Urogynaecology, Magdala Ave, London N19 5NF, UK \\ ${ }^{5}$ Department of Biomedical Sciences, Nazarbayev University, School of Medicine, Astana, Kazakhstan \\ ahttp://orcid.org/0000-0003-3914-5154 \\ bhttp://orcid.org/0000-0002-2868-4497
}

\section{Abstract}

Several different approaches have been designed by physicians in order to preserve fertility in younger patients with endometrial carcinoma. There are various options offering different advantages, but hysteroscopic resection of pathologic endometrial tissue with placement of a Levonorgestrel Intrauterine Device has proven to be the most successful in allowing patients to conceive and give birth afterwards. However, conservative treatments should only be considered in patients with low-grade and low-stage endometrial tumours. There are many published studies which have sought out a preferable approach to treating endometrial cancer whilst preserving fertility. However, more research on this matter is needed to allow a better understanding as to which techniques/approaches are optimal. In this review, we will summarise the current available treatment options for endometrial cancer in patients of reproductive age.

Keywords: endometrial cancer, fertility preservation, conservative management intrauterine system, IUD, hysteroscopy

\section{Introduction}

Endometrial cancer (EC), also known as adenocarcinoma of the endometrium, is the most common malignancy of the female genital tract in developed countries [1, 2]. In the United States, EC incidence was 61,380 new uterine cancer cases in 2017, with 10,920 deaths resulting from the disease [1, 2]. In the epidemiological study by Lortet-Tieulent et al [3], the EC incidence rate was found to increase over time in several countries. The highest rates were in North America, Eastern and Northern Europe (19 cases per 100,000 among whites in the United States, 95\% confidence interval $[\mathrm{Cl}]=18$ to 20 , and in Slovakia, $95 \% \mathrm{Cl}=18$ to 21 ), and the lowest rates were in middle-income countries (South Africa $1,95 \% \mathrm{Cl}=0$ to 3 , and India $3,95 \% \mathrm{Cl}=3$ to 4 ) [3].

Correspondence to: Gulzhanat Aimagambetova Email: gulzhanat.aimagambetova@nu.edu.kz

ecancer 2020, 14:1030

https://doi.org/10.3332/ecancer.2020.1030

Published: 06/05/2020

Received: 25/11/2019

Publication costs for this article were supported by ecancer (UK Charity number 1176307).

Copyright: $($ ) the authors; licensee ecancermedicalscience. This is an Open Access article distributed under the terms of the Creative Commons Attribution License (http:// creativecommons.org/licenses/by/3.0), which permits unrestricted use, distribution, and reproduction in any medium, provided the original work is properly cited. 
Although rare in young patients, cancer of the endometrium can affect reproductive age women (12-51 years) [4]. It has been estimated that worldwide each year, EC develops in about 142,000 women [5]. Despite an overall 5-year survival of $80 \%$, the estimated annual mortality rate is 42,000 [6]. The majority of cases are diagnosed in post-menopausal patients averaging around 75 years of age [5, 7]. However, women of reproductive age (as young as 12) can also develop this dangerous type of cancer [7].

The etiology and pathogenesis of EC have not yet been fully understood. Currently, epigenetic modifications were reported to be useful in the explanation of disease-specific features. For a better understanding of EC etiology, MiRNAs that act as part of the epigenetic machinery should be studied. It is known that TrkB-STAT3-miR-204-5p regulatory circuitry controls endometrial carcinoma cells [8]. Dysregulation of miRNA-204 mediates migration and invasion of endometrial carcinoma. Researchers identified suppression of miR-204-5p in endometrial carcinoma compared to miRNA expression in normal tissues based on validation from the Cancer Genome Atlas (TCGA) dataset [8]. MiR204-5p expression was found to be lower in the endometrial carcinoma tissues than in adjacent normal tissues from TCGA.

Risk factors for uterine neoplasms include early menarche, nulliparity, late age at menopause, increased levels of estrogen caused by obesity, diabetes, high-fat diet, advanced age ( $\geq 55$ years) and tamoxifen use [1]. Therefore, the growing incidence of EC could be attributed to increased life expectancy and obesity. Most EC is caused by sporadic mutations. However, genetic mutations could cause EC in about $5 \%$ of patients, which occurs 10 to 20 years before sporadic cancer [1, 9].

Postmenopausal bleeding is the main characteristic symptom that leads to investigations and early-stage diagnosis [10]. This is easily recognised in women that have already gone through menopause, however, this irregular bleeding can remain difficult to identify in younger women who are still menstruating regularly. The investigations that help with a diagnosis are transvaginal ultrasound measuring of endometrial thickness, hysteroscopy [11-13] and pathohistological analysis of endometrial biopsies [14, 15].

Adenocarcinomas make up the majority of EC [16]. They are derived from the epithelial cells that line the endometrium [17]. They can be classified into two types (Type 1 and Type 2) [18]. Type 1 endometrial adenocarcinomas are more common and tend to develop in a younger cohort of women including those that are perimenopausal [19]. They are often estrogen-dependent, low-grade and minimally invasive which is the reason that they are linked to a better prognosis. They are usually seen in cases of prolonged unopposed estrogen exposure [20].

Type 2 endometrial carcinomas tend to surface in a slightly older population that is postmenopausal [19]. They are not estrogen-dependent, typically aggressive, high grade and deeply invade the myometrium, hence having a poorer prognosis [21]. Analysing histological characteristics of the endometrial tumour helps to determine the prognosis.

Currently, the abovementioned traditional view of the pathogenesis of EC is changing after the molecular studies by TCGA, which issued an integrated report of genomic, transcriptomic and proteomic profiles in 373 patients diagnosed with EC [22]. Molecular data have been used to further stratify risk categories. The researchers determined four prognostic categories for classification of EC: (1) polymerase $\varepsilon$ ultramutated, (2) microsatellite instability hypermutated, (3) low copy number and (4) high copy number [23].

Several new agents are under evaluation for treating patients with metastatic, recurrent and persistent EC. Molecular characterisation has also been pursued potential therapeutic targets in EC, focusing on frequently mutated pathways, such as PI3K/PTEN/AKT/mTOR. According to expert opinion, in the near future, new studies with dual inhibitors or multi-pathways inhibitors as mono or combination therapies with conventional chemotherapy or other targeted drugs may provide more promising data. Moreover, the evaluation of new serum and histological biomarkers is an attractive strategy for patient selection [24].

Optimal management of patients with complex atypical hyperplasia or EC who desire future fertility is unknown [25]. However, some conservative methods have been introduced in order to preserve female fertility [26-28]. The aim of our review is to summarise heterogeneous literature sources and makes the data more understandable.

\section{Minimally invasive interventions}

After proper surgical work-up [29], surgical removal of the uterus with the fallopian tubes and ovaries is the main treatment of choice. Over the past years, clinical practice develops in a direction to minimally invasive approaches to total hysterectomy with bilateral 
salpingo-oophorectomy (TH/BSO) and lymph node assessment, especially in young patients in patients with early-stage EC [1, 30]. Although these procedures may be performed by any surgical route (laparoscopic, robotic, vaginal and abdominal), the standard in those with the apparent uterine-confined disease is to perform the procedure via a minimally invasive approach [1, 31]. There are still debates as to which type of procedure is deemed most effective [32].

Efficacy of the minimally invasive interventions was justified in a study that compared laparoscopy versus laparotomy approach to the treatment of EC among 2,616 patients with clinical stage I to IIA of the disease [1, 33, 34]. Interestingly enough, fewer postoperative adverse events and shorter stay in hospital occurred with laparoscopy compared with laparotomy. Recurrence rates were $11.4 \%$ for laparoscopy versus $10.2 \%$ for laparotomy. The 5 -year overall survival rate was $84.8 \%$ [1, 34]. However, another study results compared the outcomes of patients with stage I endometrial carcinoma $(n=760)$, who randomly underwent an abdominal or laparoscopic hysterectomy, reveals no significant differences (at a median follow-up of 4.5 years, disease-free survival was $81.3 \%$ for laparotomy versus $81.6 \%$ for laparoscopy) [35].

Regarding the robotic surgical approach, a review of previously published data on the efficacy of laparoscopic versus robotic surgery for hysterectomies suggests that robotic hysterectomies (RHs) take longer but may be associated with a shorter hospital stay [36]. On the other hand, in recent meta-analysis, researchers show that $\mathrm{RH}$ in EC may have advantages in reducing overall complications, length of hospital admission, estimated blood loss, transfusion and readmission compared to those for open hysterectomy and laparoscopic hysterectomy [36, 37]. Therefore, RH may be a generally safer and better option than for patients with EC.

Furthermore, in the last decades, the evaluation of sentinel lymph node utilising a robotic platform for EC staging has gained evidence among gynaecologic oncologists in parallel with the important role of minimally invasive surgical approaches [38]. This approach will decrease the number of lymphadenectomies for low-risk early-stage EC.

Depending on the tumour staging, radiotherapy and chemotherapy may also be necessary for the treatment of EC [39, 40].

\section{Fertility-sparing therapy}

Although the primary treatment of EC is usually a hysterectomy, continuous progestin-based therapy may be considered for a selected group of young patients with Grade 1, stage IA (non-invasive) disease who wish to preserve their fertility [1, 41, 42]. It may also be used for young patients with endometrial hyperplasia who desire fertility preservation.

While considering fertility-sparing therapy, all of the following criteria must be met [1]:

1. Well-differentiated (grade 1) endometrioid adenocarcinoma on dilation and curettage (D\&C) confirmed by expert pathology review

2. Disease limited to the endometrium on MRI (preferred) or transvaginal ultrasound

3. Absence of suspicious or metastatic disease on imaging

4. No contraindications to medical therapy or pregnancy

5. Patients should undergo counselling that fertility-sparing option is NOT standard of care for the treatment of endometrial carcinoma

Selected patients, who will meet all the criteria, may require genetic counselling and testing. Furthermore, TH/BSO with surgical staging is recommended after childbearing is complete, if therapy is not effective, or if progression occurs. Fertility-sparing therapy is not recommended for patients with high-grade endometrioid adenocarcinomas, uterine serous carcinoma, clear cell carcinoma and carcinosarcoma [1].

\section{Progestins (high/low dose)}

According to the published literature, progestin tends to be the most frequent type of conservative treatment of early-stage EC [43]. In the 90's, it was first described as a successful hormonal treatment that allowed patients with EC to become pregnant [44, 45]. Since then, it has become increasingly more popular in terms of non-invasive treatments. 
Continuous progestin therapy may include megestrol acetate (MA), medroxyprogesterone acetate (MPA) or an intrauterine device containing levonorgestrel [1, 46-48]. To this day, there is still no definitive answer as to what is the optimal dose and duration of treatment that produces the best effects. However, the most common reported doses to vary between 250 and $600 \mathrm{mg} /$ day for MPA and 160-480 mg/ day for MA [49].

A complete response of treatment occurs in about $50 \%$ of patients on average around 5.5 months of continuous use [1, 47, 49]. Despite a positive response to progestin use, several cases have reported a recurrence rate in about one-fifth of patients taking progestins [47]. Recurrence was reported to take place after an average of 23+/- months [49]. Relapse also did occur in a very small percentage of patients after they initially reached a complete response to conservative progestin treatment [47].

Unfortunately, progestin supplementation has its shortcomings [50, 51]. Long-term oral administration of progesterone can cause certain adverse effects in patients including abdominal cramps, depression, dizziness and headaches [52]. For this reason, complete compliance has proven to be quite difficult to achieve from patients in many studies [53-55]. Therefore, other conservative approaches have been researched, including levonorgestrel-releasing intrauterine devices and the use of gonadotropin-releasing hormones. These may either be used separately or together.

Another study combined MA with tamoxifen and gonadotropin-releasing hormone analogue ( $\mathrm{GnRHa}$ ) and found that $89 \%$ of patients reached complete remission after therapy with this combination of hormones [56]. Furthermore, $45 \%$ of patients were able to successfully conceive after the treatment. The prognosis was good in the majority of these patients [56].

In patients receiving progestin-based therapies, the NCCN panel recommends close monitoring with endometrial sampling every 3 to 6 months [1]. TH/BSO with staging is recommended (1) after childbearing is complete, (2) if patients have documented progression with biopsies and (3) if EC is still present after 6 to 12 months of progestin-based therapy [1, 42, 57].

The use of progestin-based therapy should be administered carefully by taking into consideration the contraindications: breast cancer, stroke, myocardial infarction, pulmonary embolism, deep vein thrombosis and smoking [1].

\section{Levonorgestrel-releasing intrauterine device}

In recent years, more and more patients accepted a levonorgestrel-releasing intrauterine device (LNG-IUD) as an option for conservative management of endometrial hyperplasia and EC $[58,59]$. It is already well known that LNG-IUD can provoke a higher progesterone concentration than oral progestin. However, results of small studies which are used LNG-IUD for EC have inconclusive results [25].

One study solely focused on patients with stage 1 grade $1 \mathrm{EC}$ with positive progesterone receptors. All patients were assessed by anaesthesiologists who deemed them unfit for surgery with general anaesthesia [60]. Out of four cases, only one patient (25\%) successfully had tumours regression in response to the LNG-IUD However, several cases have been reported that the LNG-IUD was not completely successful in preventing atypical endometrial hyperplasia from progressing to an adenocarcinoma. This raises questions about the efficacy of this approach.

In a more recent study of 46 patients, diagnosed with complex atypical hyperplasia or early grade EC, who were treated with the LNG-IUD, resulted in a return to normal histology in a majority of patients-the overall response rate was $75 \%(95 \% \mathrm{Cl}=57-89)$ at 6 months [25].

A report from the recent meta-analysis states that for patients with EC/atypical hyperplasia, treatments with progestin, with or without LNGIUD, or LNG-IUD alone can reach a good complete response rate; however, the pregnancy outcomes might be worse in patients treated with LNG-IUD alone [2]. Therefore, conservative treatments should be approached with caution and further randomised-controlled studies are necessary to confirm and update these data.

\section{Progestin use with levonorgestrel-releasing intrauterine device}

One Korean study tested the effectiveness of oral progestins (MPA) with the use of LNG-IUD [61]. Patients who were under 40 years, who desired to preserve their fertility and who had a low-grade EC were included in the study. All patients were fitted with an LNG-IUD and were 
supplemented to take $500 \mathrm{mg}$ daily of MPA. The complete remission rate was $87.5 \%$ and this was achieved approximately 9.8 months after the start of treatment. Around $12 \%$ of patients continued to have successful pregnancies [61]. It seems that combined treatment is more successful than the use of an LNG-IUD by itself.

\section{Levonorgestrel intrauterine device with gonadotropin releasing hormone agonists}

A meta-analysis helped shed some light on the utilisation of LNG-IUD in combination with gonadotropin-releasing hormone agonists (GnRHa). In this study, data from six investigations were summarised which comprised 90 patients with an early stage of EC [59]. A total of 75.5\% $(68 / 90)$ of patients achieved complete response $(95 \% \mathrm{Cl}, 60.4 \%-82.5 \%)$. Among the 68 patients, 34 patients were prepared for pregnancy, and 20 patients got pregnant successfully, of which 13 patients conceived successfully via ART and 3 via natural method [58].

A Russian study found $72 \%$ of patients with early-stage endometrial adenocarcinoma who used LNG-IUD with GnRHa had reached complete remission [62]. Eight patients from the study developed 10 conceptions that later turned into 8 live births [62]. These positive results raise the question if the involvement of progestins in the conservative treatment of EC is necessary.

Another study with a similar design found $88 \%$ of women with EC who had GnRHa injections with an LNG-IUD had a complete response after about 18.7 months. These results are very promising [63].

Based on the abovementioned data, we can conclude that recent intrauterine progestin therapy, such as LNG-IUD combined with GnRHa, has a satisfactory pregnancy rate and low recurrence rate [59].

\section{Hysteroscopic resection followed by progestin therapy}

The results of the recent meta-analysis show that patients who received hysteroscopic resection followed by progestin therapy achieved the highest complete response rate [59]. There were six similar studies analysed with a total number of 73 presumed stage IA EC patients who underwent hysteroscopic resection of the lesions, the endometrium adjacent to the carcinoma, and the myometrium underlying the tumour followed by progestin therapy. A total of $89 \%(65 / 73)$ of patients achieved a pathological complete response, with a pooled complete response of $95.3 \%(95 \% \mathrm{Cl}, 87.8 \%-100 \%)$.

The other study focused on the efficacy of surgical resection of the diseased endometrial followed by oral therapy of MA 160 mg/day commences 5 days after the procedure for a total of 6 months [64]. All patients were nulliparous at diagnosis of endometrial cancer. More than $65 \%$ of patients successfully gave birth to five infants without any reproductive assistance. They were able to conceive on average 24 months after the end of therapy. These results are exceptionally promising, however, physicians must take great care while curetting all necessary areas of the tumour in order to ensure appropriate removal [64]. Further well-designed, randomised controlled trials are necessary to confirm and update these data.

\section{Hysteroscopic resection followed by insertion of levonorgestrel-releasing intrauterine device}

Several studies have looked at the effect of physically resecting the pathologic tissue through hysteroscopy and then apply an LNG-IUD. They found that $7 \%$ of patients had a cancer recurrence, and $78 \%$ of patients with endometrial carcinoma showed a complete response [65]. Almost half (45\%) of the patients that achieved a complete response, after removal of LNG-IUD were able to conceive naturally and give birth within 12 months of receiving treatment. The results and success ratios were quite similar to those of patients who receive progestins as a form of conservative treatment [65].

Recently, hysteroscopic resection of atypical hyperplasia and EC followed by oral or intrauterine-released progestins has been demonstrated to be an effective fertility-sparing treatment [66]. The researchers' findings strongly suggest that hysteroscopic resection followed by the insertion of LNG-IUD might have a lower relapse rate than progestin therapies alone, with the similar response and pregnancy rates [66]. 


\section{Conclusion}

Women of reproductive age experiencing endometrial cancer require conservative management and counselling for fertility-sparing options. The management of young women with endometrial cancer and atypical hyperplasia varies among clinicians. The use of progestins seems to offer very good results in treating early-stage endometrial cancer and is useful for fertility preservation. However, the optimal treatment is still debated and no consensus has been reached yet. Furthermore, fertility-sparing management should not be restricted to infertile women. Operative hysteroscopy should be the preferred endometrial sampling method because of its association with a higher remission rate. The guidance for managing conservatively young patients with endometrial cancer should be provided, but should never replace the individual approach for care and management as each patient has different characteristics as well as different needs and expectations.

\section{Acknowledgments}

The authors would like to acknowledge the Nazarbayev University School of Medicine for the support that enabled completion on this review article.

\section{Conflicts of interest}

The authors declare that they have no conflict of interests with respect to this paper.

\section{Funding declaration}

The authors did not receive specific funding for this work.

\section{Authors' contributions}

MT formulated the review. MN, ST, GB and GA planned the review, conducted the literature search and wrote the initial draft. MT and GA performed the final review of the manuscript.

\section{References}

1. Koh WJ, Abu-Rustum NR, and Bean S, et al (2018). Uterine neoplasms, version 1.2018, NCCN clinical practice guidelines in oncology J Natl Compr Canc Netw 16(2) 170-199 https://doi.org/10.6004/jnccn.2018.0006 PMID: 29439178

2. Wei J, Zhang W, and Feng L, et al (2017) Comparison of fertility-sparing treatments in patients with early endometrial cancer and atypical complex hyperplasia: a meta-analysis and systematic review Medicine (Baltimore) 96(37) e8034 https://doi.org/10.1097/ MD.0000000000008034

3. Lortet-Tieulent J, Ferlay J, and Bray F, et al (2018) International patterns and trends in endometrial cancer incidence, 1978-2013 J Natl Cancer Inst 110(4) 354-361 https://doi.org/10.1093/jnci/djx214

4. Casarin J, Bogani G, and Serati M, et al (2019) Presence of glandular cells at the preoperative cervical cytology and local recurrence in endometrial cancer Int J Gynecol Pathol https://doi.org/10.1097/PGP.0000000000000642 PMID: 31651558 
5. Amant F, Moerman P, and Neven P, et al (2005) Endometrial cancer Lancet 366(9484) 491-505 https://doi.org/10.1016/S01406736(05)67063-8 PMID: 16084259

6. Parazzini F, La Vecchia C, and Bocciolone L, et al (1991) The epidemiology of endometrial cancer Gynecol Oncol 41(1) 1-6 https://doi. org/10.1016/0090-8258(91)90246-2 PMID: 2026352

7. Vitale SG, Capriglione S, and Zito G, et al (2019) Management of endometrial, ovarian and cervical cancer in the elderly: current approach to a challenging condition Arch Gynecol Obstet 299(2) 299-315 https://doi.org/10.1007/s00404-018-5006-z

8. Guo S, Yang J, and Wu M, et al (2019) Clinical value screening, prognostic significance and key pathway identification of miR-204-5p in endometrial carcinoma: a study based on the Cancer Genome Atlas (TCGA), and bioinformatics analysis Pathol Res Pract 215(5) 1003-1011 https://doi.org/10.1016/j.prp.2019.02.007 PMID: 30910254

9. Resnick KE, Hampel H, and Fishel R, et al (2009) Current and emerging trends in Lynch syndrome identification in women with endometrial cancer Gynecol Oncol 114 128-134 https://doi.org/10.1016/j.ygyno.2009.03.003 PMID: 19375789 PMCID: 2841434

10. Tabor A, Watt HC, and Wald NJ (2002) Endometrial thickness as a test for endometrial cancer in women with postmenopausal vaginal bleeding Obstet Gynecol 99(4) 663-670 PMID: 12039131

11. Cignini P, Vitale SG, and Laganà AS, et al (2017) Preoperative work-up for definition of lymph node risk involvement in early stage endometrial cancer: 5-year follow-up Updates Surg 69(1) 75-82 https://doi.org/10.1007/s13304-017-0418-z PMID: 28108938

12. De Franciscis P, Riemma G, and Schiattarella A, et al (2019) Concordance between the hysteroscopic diagnosis of endometrial hyperplasia and histopathological examination Diagnostics (Basel) 9(4) pii: E142

13. Chiofalo B, Mazzon I, and Di Angelo Antonio S, et al (2019) Hysteroscopic evaluation of endometrial changes in breast cancer women with or without hormone therapies: results from a large multicenter cohort study J Minim Invasive Gynecol pii: S1553-4650(19)30365-6

14. Clark TJ, Voit D, and Gupta JK, et al (2002) Accuracy of hysteroscopy in the diagnosis of endometrial cancer and hyperplasia: a systematic quantitative review JAMA 288(13) 1610-1621 https://doi.org/10.1001/jama.288.13.1610 PMID: 12350192

15. Clark TJ, Mann CH, and Shah N, et al (2002) Accuracy of outpatient endometrial biopsy in the diagnosis of endometrial cancer: a systematic quantitative review BJOG 109(3) 313-321 https://doi.org/10.1111/j.1471-0528.2002.01088.x PMID: 11950187

16. Morice P, Leary A, and Creutzberg C, et al (2016) Endometrial cancer Lancet 387(10023) 1094-1108 https://doi.org/10.1016/S01406736(15)00130-0

17. Frumovitz M, Singh DK, and Meyer L, et al (2004) Predictors of final histology in patients with endometrial cancer Gynecol Oncol 95(3) 463-468 https://doi.org/10.1016/j.ygyno.2004.07.016 PMID: 15581947

18. Bokhman JV (1983) Two pathogenetic types of endometrial carcinoma Gynecol Oncol 15(1) 10-17 https://doi.org/10.1016/00908258(83)90111-7 PMID: 6822361

19. Felix AS, Weissfeld JL, and Stone RA, et al (2010) Factors associated with Type I and Type II endometrial cancer Cancer Causes Control 21(11) 1851-1856 https://doi.org/10.1007/s10552-010-9612-8 PMID: 20628804 PMCID: 2962676

20. Emons G, Fleckenstein G, and Hinney B, et al (2000) Hormonal interactions in endometrial cancer Endocr Relat Cancer 7(4) 227-242 https://doi.org/10.1677/erc.0.0070227

21. Setiawan VW, Yang HP, and Pike MC, et al (2013) Type I and II endometrial cancers: have they different risk factors? J Clin Oncol 31(20) 2607 https://doi.org/10.1200/JCO.2012.48.2596 PMID: 23733771 PMCID: 3699726

22. Levine D, Getz G, and Gabriel S (2013) Integrated genomic characterization of endometrial carcinoma Nature 497 67-73 https://doi. org/10.1038/nature12113 PMID: 23636398 PMCID: 3704730 
23. Kim SI, Lee JW, and Lee N, et al (2018) LYL1 gene amplification predicts poor survival of patients with uterine corpus endometrial carcinoma: analysis of the cancer genome atlas data BMC Cancer 18(1) 494 https://doi.org/10.1186/s12885-018-4429-z PMID: 29716549 PMCID: $\underline{5930686}$

24. Barra F, Evangelisti G, and Ferro Desideri L (2013) Investigational PI3K/AKT/mTOR inhibitors in development for endometrial cancer Expert Opin Investig Drugs 28(2) 131-142 https://doi.org/10.1080/13543784.2018.1558202

25. Pal N, Broaddus RR, and Urbauer DL, et al (2018) Treatment of low-risk endometrial cancer and complex atypical hyperplasia with the levonorgestrel-releasing intrauterine device Obstet Gynecol 131(1) 109-116 https://doi.org/10.1097/AOG.0000000000002390

26. Vitale SG, Rossetti D, and Tropea A, et al (2017) Fertility sparing surgery for stage IA type I and G2 endometrial cancer in reproductive-aged patients: evidence-based approach and future perspectives Updates Surg 69(1) 29-34 https://doi.org/10.1007/s13304-0170419-y PMID: 28188573

27. Rossetti D, Bogani G, and Carnelli M, et al (2014) Efficacy of IVF following conservative management of endometrial cancer Gynecol Endocrinol 30(4) 280-281 https://doi.org/10.3109/09513590.2014.892065 PMID: 24568557

28. Laganà AS, La Rosa VL, and Rapisarda AM, et al (2017) Comment on: "Needs and priorities of women with endometrial and cervical cancer" J Psychosom Obstet Gynaecol 38(1) 85-86 https://doi.org/10.1080/0167482X.2016.1244186

29. Franchi M, Garzon S, and Zorzato PC, et al (2019) PET-CT scan in the preoperative workup of early stage intermediate- and high-risk endometrial cancer Minim Invasive Ther Allied Technol 6 1-8 https://doi.org/10.1080/13645706.2019.1624576

30. Scalici J, Laughlin BB, and Finan MA, et al (2015) The trend towards minimally invasive surgery (MIS) for endometrial cancer: an ACSNSQIP evaluation of surgical outcomes Gynecol Oncol 136 512-515 https://doi.org/10.1016/j.ygyno.2014.11.014

31. Boggess JF, Gehrig PA, and Cantrell L, et al (2008) A comparative study of 3 surgical methods for hysterectomy with staging for endometrial cancer: robotic assistance, laparoscopy, laparotomy Am J Obst Gynecol 199(4) 360.e1-360.e9. https://doi.org/10.1016/j. ajog.2008.08.012

32. Vitale SG, Valenti G, and Gulino FA, et al (2016) Surgical treatment of high stage endometrial cancer: current perspectives Updates Surg 68(2) 149-154 https://doi.org/10.1007/s13304-015-0340-1 PMID: 26826083

33. Walker JL, Piedmonte MR, and Spirtos NM, et al (2009) Laparoscopy compared with laparotomy for comprehensive surgical staging of uterine cancer: Gynecologic Oncology Group Study LAP2 J Clin Oncol 27 5331-5336 https://doi.org/10.1200/JCO.2009.22.3248 PMID: 19805679 PMCID: 2773219

34. Walker JL, Piedmonte MR, and Spirtos NM, et al (2012) Recurrence and survival after random assignment to laparoscopy versus laparotomy for comprehensive surgical staging of uterine cancer: Gynecologic Oncology Group LAP2 Study J Clin Oncol 30 695-700 https://doi.org/10.1200/JCO.2011.38.8645 PMID: 22291074 PMCID: 3295548

35. Janda M, Gebski V, and Davies LC, et al (2017) Effect of total laparoscopic hysterectomy vs total abdominal hysterectomy on diseasefree survival among women with stage I endometrial cancer: a randomized clinical trial JAMA 317 1224-1233 https://doi.org/10.1001/ jama.2017.2068 PMID: 28350928

36. Zanagnolo V, Achilarre MT, and Maruccio M, et al (2018) Might robotic-assisted surgery become commonplace in endometrial cancer treatment? Expert Rev Anticancer Ther 18(6) 507-509 https://doi.org/10.1080/14737140.2018.1469981 PMID: 29708002

37. Park DA, Lee DH, and Kim SW, et al (2016) Comparative safety and effectiveness of robot-assisted laparoscopic hysterectomy versus conventional laparoscopy and laparotomy for endometrial cancer: a systematic review and meta-analysis Eur J Surg Oncol $421303-$ 1314 https://doi.org/10.1016/j.ejso.2016.06.400 PMID: 27439723

38. Centurioni MG, Barra F, and Gustavino C, et al (2019) Sentinel-node mapping by intraoperative near-infrared fluorescence in the robotic surgical treatment of endometrial cancer J Gynecol Surg 35(4) 205-207 https://doi.org/10.1089/gyn.2018.0106 
39. Hogberg T, Signorelli M, and De Oliveira CF, et al (2010) Sequential adjuvant chemotherapy and radiotherapy in endometrial cancerresults from two randomised studies. Eur J Cancer 46(13) 2422-2431 https://doi.org/10.1016/j.ejca.2010.06.002 PMID: 20619634 PMCID: 3552301

40. Rossetti D, Vitale SG, and Gulino FA, et al (2016) Concomitant chemoradiation treatment in selected Stage I endometrioid endometrial cancers Eur J Gynaecol Oncol 37(5) 657-661 PMID: 29787005

41. Gunderson CC, Fader AN, and Carson KA, et al (2012) Oncologic and reproductive outcomes with progestin therapy in women with endometrial hyperplasia and grade 1 adenocarcinoma: a systematic review Gynecol Oncol 125 477-482 https://doi.org/10.1016/j. ygyno.2012.01.003 PMID: 22245711

42. Hubbs JL, Saig RM, and Abaid LN, et al (2013) Systemic and local hormone therapy for endometrial hyperplasia and early adenocarcinoma Obstet Gynecol 121 1172-1180 https://doi.org/10.1097/AOG.0b013e31828d6186 PMID: 23812449

43. Gotlieb WH, Beiner ME, and Shalmon B, et al (2003) Outcome of fertility-sparing treatment with progestins in young patients with endometrial cancer Obstet Gynecol 102(4) 718-725 PMID: 14551001

44. Randall TC and Kurman RJ (1997) Progestin treatment of atypical hyperplasia and well-differentiated carcinoma of the endometrium in women under age 40 Obstet Gynecol 90(3) 434-440 https://doi.org/10.1016/S0029-7844(97)00297-4 PMID: 9277658

45. Kim YB, Holschneider $\mathrm{CH}$, and Ghosh $\mathrm{K}$, et al (1997) Progestin alone as primary treatment of endometrial carcinoma in premenopausal women: report of seven cases and review of the literature Cancer 79(2) 320-327 https://doi.org/10.1002/(SICI)10970142(19970115)79:2<320::AID-CNCR15>3.0.CO;2-2 PMID: 9010105

46. Eftekhar Z, Izadi-Mood N, and Yarandi F, et al (2009) Efficacy of megestrol acetate (megace) in the treatment of patients with early endometrial adenocarcinoma: our experiences with 21 patients Int J Gynecol Cancer 19(2) 249-252 https://doi.org/10.1111/ IGC.0b013e31819c5372 PMID: 19396003

47. Lowe MP, Bender D, and Sood AK, et al (2002) Two successful pregnancies after conservative treatment of endometrial cancer and assisted reproduction Fertil Steril 77(1) 188-189 https://doi.org/10.1016/S0015-0282(01)02937-5 PMID: 11779615

48. Baker J, Obermair A, and Gebski V, et al (2012) Efficacy of oral or intrauterine device-delivered progestin in patients with complex endometrial hyperplasia with atypia or early endometrial adenocarcinoma: a meta-analysis and systematic review of the literature Gynecol Oncol 125 263-270 https://doi.org/10.1016/j.ygyno.2011.11.043

49. Yamazawa K, Hirai M, and Fujito A, et al (2007) Fertility-preserving treatment with progestin, and pathological criteria to predict responses, in young women with endometrial cancer Hum Reprod 22(7) 1953-1958 https://doi.org/10.1093/humrep/dem088 PMID: 17449880

50. Laganà AS, Palmara V, and Granese R, et al (2014) Desogestrel versus danazol as preoperative treatment for hysteroscopic surgery: a prospective, randomized evaluation Gynecol Endocrinol 30(11) 794-797 https://doi.org/10.3109/09513590.2014.929658 PMID: 24919887

51. Sansone A, De Rosa N, and Giampaolino P, et al (2018) Effects of etonogestrel implant on quality of life, sexual function, and pelvic pain in women suffering from endometriosis: results from a multicenter, prospective, observational study Arch Gynecol Obstet 298(4) 731-736 https://doi.org/10.1007/s00404-018-4851-0 PMID: 30074068

52. Laganà AS, Giacobbe V, and Triolo O, et al (2016) Dienogest as preoperative treatment of submucous myomas for hysteroscopic surgery: a prospective, randomized study Gynecol Endocrinol 32(5) 408-411 https://doi.org/10.3109/09513590.2015.1128409 PMID: 26743136

53. Signorelli M, Caspani G, and Bonazzi C, et al (2009) Fertility-sparing treatment in young women with endometrial cancer or atypical complex hyperplasia: a prospective single-institution experience of 21 cases. BJOG 116(1) 114-118 https://doi.org/10.1111/j.14710528.2008.02024.x 
54. Laganà AS, Vitale SG, and Granese R, et al (2017) Clinical dynamics of Dienogest for the treatment of endometriosis: from bench to bedside Expert Opin Drug Metab Toxicol 13(6) 593-596 https://doi.org/10.1080/17425255.2017.1297421 PMID: 28537213

55. Laganà AS, Vitale SG, and Muscia V, et al (2017) Endometrial preparation with Dienogest before hysteroscopic surgery: a systematic review Arch Gynecol Obstet 295(3) 661-667 https://doi.org/10.1007/s00404-016-4244-1

56. Wang CB, Wang $\mathrm{CJ}$, and Huang $\mathrm{HJ}$, et al (2002) Fertility-preserving treatment in young patients with endometrial adenocarcinoma Cancer 94(8) 2192-2198 https://doi.org/10.1002/cncr.10435 PMID: 12001117

57. Mehasseb MK and Latimer JA (2012) Controversies in the management of endometrial carcinoma: an update Obstet Gynecol Int 2012 676032 https://doi.org/10.1155/2012/676032 PMID: 22518164 PMCID: 3306928

58. Dhar KK, NeedhiRajan T, and Koslowski M, et al (2005) Is levonorgestrel intrauterine system effective for treatment of early endometrial cancer? Report of four cases and review of the literature. Gynecol Oncol 97(3) 924-927 https://doi.org/10.1016/j.ygyno.2004.10.031 PMID: 15943993

59. Fan Z, Li H, and Hu R, et al (2018) Fertility-preserving treatment in young women with grade 1 presumed stage IA endometrial adenocarcinoma: a meta-analysis Int J Gynecol Cancer 28(2) 385-393 https://doi.org/10.1097/IGC.0000000000001164

60. Giannopoulos T, Butler-Manuel S, and Tailor A (2004) Levonorgestrel-releasing intrauterine system (LNG-IUS) as a therapy for endometrial carcinoma Gynecol Oncol 95(3) 762-764 https://doi.org/10.1016/j.ygyno.2004.09.010 PMID: 15582001

61. Kim MK, Seong SJ, and Lee TS, et al (2012) Treatment with medroxyprogesterone acetate plus levonorgestrel-releasing intrauterine system for early-stage endometrial cancer in young women: single-arm, prospective multicenter study: Korean gynecologic oncology group study (KGOG2009) Jpn J Clin Oncol 42(12) 1215-1218 https://doi.org/10.1093/jjco/hys171 PMID: 23071290

62. Pronin SM, Novikova OV, and Andreeva JY, et al (2015) Fertility-sparing treatment of early endometrial cancer and complex atypical hyperplasia in young women of childbearing potential Int J Gynecol Cancer 25(6) 1010-1014 https://doi.org/10.1097/ IGC.0000000000000467 PMID: 25950126

63. Zhou H, Cao D, and Yang J, et al (2017) Gonadotropin-releasing hormone agonist combined with a levonorgestrel-releasing intrauterine system or letrozole for fertility-preserving treatment of endometrial carcinoma and complex atypical hyperplasia in young women Int J Gynecol Cancer 27(6) 1178-1182 https://doi.org/10.1097/IGC.0000000000001008 PMID: 28562472

64. Mazzon I, Corrado G, and Masciullo V, et al (2010) Conservative surgical management of stage IA endometrial carcinoma for fertility preservation Fertil Steril 93(4) 1286-1289 https://doi.org/10.1016/j.fertnstert.2008.12.009

65. Laurelli G, Di Vagno G, and Scaffa C, et al (2011) Conservative treatment of early endometrial cancer: preliminary results of a pilot study Gynecol Oncol 120(1) 43-46 https://doi.org/10.1016/j.ygyno.2010.10.004

66. Giampaolino P, Di Spiezio Sardo A, and Mollo A, et al (2019) Hysteroscopic endometrial focal resection followed by levonorgestrel intrauterine device insertion as a fertility-sparing treatment of atypical endometrial hyperplasia and early endometrial cancer: a retrospective study J Minim Invasive Gynecol 26(4) 648-656 https://doi.org/10.1016/j.jmig.2018.07.001 